\title{
Peer-review website vows to fight scientist's subpoena
}

\section{Cancer researcher Fazlul Sarkar claims that anonymous comments on PubPeer cost him a job.}

\section{Richard Van Noorden}

14 November 2014

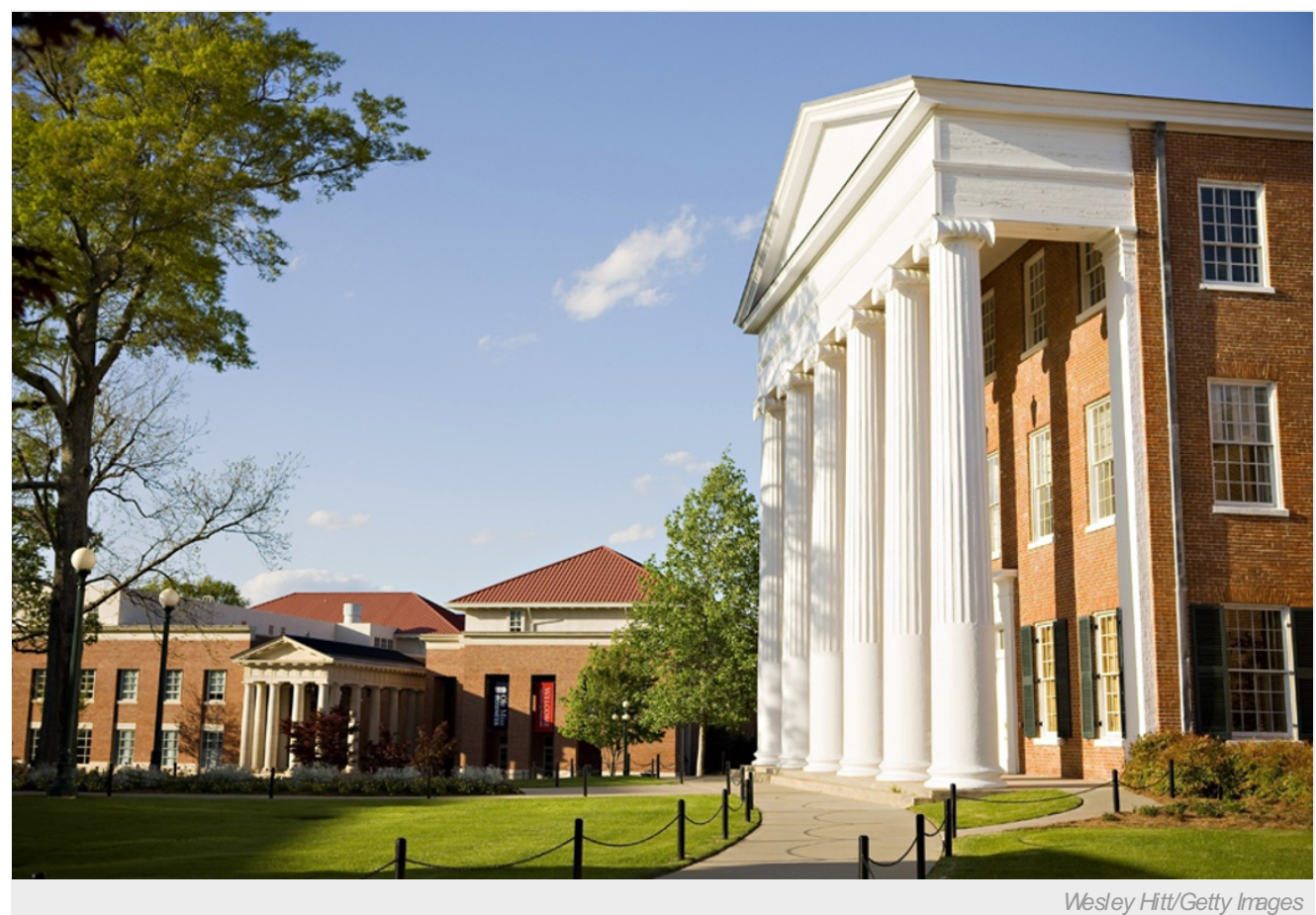

The University of Mississippi rescinded a job offer to a prospective faculty member over anonymous online comments about his work — and over what it says was his failure to address its concerns.

PubPeer.com, a website for discussing science articles, plans to contest legal action by a scientist who is trying to force it to hand over information about anonymous commenters. Cancer researcher Fazlul Sarkar is seeking clues that could reveal the commenters' identities, because he says they made defamatory remarks about his work that led him to lose a job.

Sarkar was at Wayne State University in Detroit, Michigan, when he accepted a tenured post at the University of Mississippi in Oxford. But the university withdrew its offer in June this year after it saw the PubPeer comments.

Sarkar, who remains at Wayne State, filed a lawsuit (see pdf of complaint) on 9 October against the unknown commenters, and subpoenaed PubPeer (pdf of subpoena) to reveal any information it held, such as the IP addresses from which comments were posted.

On 11 November, both sides in the dispute agreed that PubPeer could have until 10 December to respond to the subpoena. And PubPeer's lawyers now say that the site's organizers (who are themselves anonymous, but say they are early-career researchers) will try to quash Sarkar's grounds for a subpoena by arguing that the comments were not in fact defamatory.

"PubPeer very strongly believes its users have a right to comment anonymously, as long as they do so lawfully," says Alex Abdo of the American Civil Liberties Union in New York, which is assisting PubPeer with the case. "What [the comments] reflect are legitimate scientific questions that should not be resolved through court proceedings, but through more discussion," he adds.

Under US law, PubPeer is protected from being sued. The First Amendment in the US Constitution also protects rights to anonymous free speech, Abdo notes. To persuade a judge that PubPeer should hand over any identifying information it holds about the commenters, a plaintiff would have to first make a strong case that the comments were defamatory. That argument involves a host of other legal debates, such as whether the commenters were acting in the public interest.

\section{Grey area}


There are concerns that the case might have a chilling effect on scientists and discourage them from leaving online comments on research papers. "If the case does proceed, it should contribute to the exploration of the poorly defined interface between the law of defamation and the scientific process," the site's moderators wrote when they first revealed the legal threat. "The case may have to resolve what is perhaps the most vexed legal issue in post-publication peer review today: if features of published data are suggestive of misconduct, is it defamatory to draw attention to those features?" they added.

Meanwhile, Sarkar's lawyer Nicholas Roumel, a partner at Nacht Law in Ann Arbor, Michigan, told Nature last month that Sarkar was also pursuing action against the University of Mississippi, but that a lawsuit had not yet been filed. "Mississippi has a statute requiring a [90-day] period of written notice before suit can be filed. We have initiated that process. We're in the waiting period. Anything can happen in that period so there is no certainty that suit will be filed," he said.

The details of how the University of Mississippi dealt with the PubPeer comments are unclear. A spokesperson for the university, Tom Eppes, explained that the threat of legal action limited what he could say, but that the university asked Sarkar to respond to the university's concerns. "He never responded or otherwise provided assistance in addressing the questions," Replying for his client Sarkar, Roumel said: "I would respectfully disagree with Mr Eppes," but did not elaborate.

Nature | doi:10.1038/nature.2014.16356 